\title{
Microstructured reactors for catalytic reactions
}

\author{
Lioubov Kiwi-Minsker, Albert Renken* \\ Ecole Polytechnique Fédérale de Lausanne, Institute of Chemical Engineering, SB-ISIC-LGRC, Station 6, CH-1015 Lausanne, Switzerland
}

Available online 10 October 2005

\begin{abstract}
This review addresses the catalytic reactions performed in microstructured reactors, which are more and more recognized in recent years as a novel approach for chemistry and chemical process industry. They are particularly suited for highly exothermic and fast reactions allowing temperature control and isothermal operation. A brief evaluation of the advantages for gas-phase, liquid-phase, and gas-liquid-solid reactions carried out in miniaturized devices is discussed. Alternative designs to achieve microstructured fluid patterns, besides microfabrication, are also described.
\end{abstract}

(C) 2005 Elsevier B.V. All rights reserved.

Keywords: Microreactor; Microstructured reactors; Catalyst; Homogeneous; Heterogeneous catalysis; Multiphase reactions

\section{Introduction}

Chemical microstructured reactors (MSR) are devices containing open paths for fluids with dimensions in the submillimeter range. Mostly MSR have multiple parallel channels with diameters between 10 and several hundred micrometers where the chemical transformation occur [1-4].

The main feature of microstructured reactors is their high surface to volume ratio in the range of $10,000-50,000 \mathrm{~m}^{2} / \mathrm{m}^{3}$ compared to more traditional chemical reactors. The specific surface in conventional laboratory and production vessels is usually $-100 \mathrm{~m}^{2} / \mathrm{m}^{3}$ and seldom exceeds $1000 \mathrm{~m}^{2} / \mathrm{m}^{3}$. Usually MSR are operated under laminar flow conditions. Accordingly, the heat transfer coefficient is inversely proportional to the channel diameter, and their values for liquids are about $10 \mathrm{~kW} /$ $\left(\mathrm{m}^{2} \mathrm{~K}\right)$ being roughly one order of magnitude higher than in the traditional heat exchangers [5]. Schubert et al. determined values for heat transfer coefficients of around $25 \mathrm{~kW} /\left(\mathrm{m}^{2} \mathrm{~K}\right)$ with water as heat transfer medium [6]. The high heat transfer allows to utilize the full potential of catalysts during highly endothermic or exothermic reactions and avoid hot-spots formation [7]. Higher reaction temperatures are attained leading to reduced reaction volumes and less amount of catalysts [8] improving the energy efficiency and reducing the operational

\footnotetext{
* Corresponding author. Tel.: +41 21693 3181; fax: +41 216933190.

E-mail address: Albert.Renken@epfl.ch (A. Renken).
}

costs. In addition, microstructures allow fast heating and cooling of reaction mixtures in open reactor systems $[9,10]$.

The small diameters of the reactor channels ensure a short radial diffusion time leading to a narrow residence time distribution (RTD). This is advantageous for consecutive processes since high selectivity to the desired intermediate is achieved. Isothermal conditions combined with short residence times and narrow RTD are the main characteristics of MSR. Avoidance of heat- and mass-transfer limitations is the main objective for the MSR development compared to more conventional apparatus.

In addition, the small inventories of reactants and products lead to inherent safety during the reactor operation. It has been reported that the MSR run safely under conditions, which lay in the explosion regime [11-15]. Small reactor dimensions facilitate the use of distributed production units at the place of consumption. This avoids the transport and storage of dangerous materials. Another aspect is the easier scale-up by multiplying the number (numbering-up) of MSR units without change of the channel geometry.

In summary, microstructured reactors are suitable for fast, highly exothermic or endothermic chemical reactions because they lead to:

- process intensification,

- inherent reactor safety,

- broader reaction conditions including up-to the explosion regime, 
- distributed production,

- faster process development.

Most examples for MSR applications concern laboratory scale, involving miniaturization, like for the distributed production of hazardous compounds like phosgene [16], or hydrogen for the production of electrical energy. Nevertheless, potential advantages of microstructured devices are not limited to process miniaturization. The incorporation of appropriately designed and targeted microstructured units within large-scale macro-devices lead to innovative design of process units of all sizes [17-19]. Up to now only few attempts have been made to transfer laboratory results into industrial production based on this microreactor innovative technology. One example for the potential implantation of MSR into industrial production is given by the DEMIS ${ }^{\circledR}$ (Demonstration Project for the Evaluation of Microreactor Technology in Industrial Systems) [20]. The epoxidation of propylene with hydrogen peroxide vapor was selected as model reaction.

A review on the MSR for gas phase reactions was recently published by Kolb and Hessel [7]. This review deals with recent publications involving catalytic gas phase reaction. In addition, catalytic multiphase reactions in MSR are also discussed.

\section{MSR for catalytic gas phase reactions}

One of the main problems in using microstructured reactors for heterogeneously catalyzed gas-phase reactions is the introduction of the catalytic active phase. Therefore, the MSR are classified here by the type of the catalytic bed and according to their design criteria.

\subsection{Packed bed reactors}

The easiest way to incorporate the catalyst into MSR is to fill microchannels with catalyst powder. The "micropacked-bed" is commonly used for catalyst screening [21-23]. But there are also examples for the use of micropacked-beds for the distributed production of chemicals. The advantage of packed-bed microreactors stems from the fact that traditional and optimized catalyst can be easily implicated. Typically, the catalyst particles have diameters in the range of 35-75 $\mu \mathrm{m}$ [24] and the MSR operates with laminar flow.

For kinetic studies of heterogeneous catalytic reactions, it is important to evaluate the catalyst under well-defined conditions excluding as much as possible temperature and concentration gradients. Cao et al. [25] developed a microchannel reactor system with effective heat exchange to decouple the transport phenomena from intrinsic kinetics of the chemical reactions. The catalyst was located in a microchannel slot with a gap width of $508 \mu \mathrm{m}$ sandwiched between two oil-heating channels. The authors used this system to study the strongly endothermic methanol reforming over $\mathrm{Pd} / \mathrm{ZnO}$ :

$$
\mathrm{CH}_{3} \mathrm{OH}+\mathrm{H}_{2} \mathrm{O} \rightarrow \mathrm{CO}_{2}+3 \mathrm{H}_{2} ; \quad \Delta_{\mathrm{r}} \mathrm{H}=59.5 \mathrm{~kJ} / \mathrm{mol}
$$

Based on the results obtained, a microscale fuel processor was developed [26] to supply a small fuel cell up to $300 \mathrm{~mW}_{\mathrm{e}}$ with hydrogen. The total volume of the fuel processor was less than $0.3 \mathrm{~cm}^{3}$. It consisted of three catalytic sections: (a) methanol steam reforming for hydrogen production; (b) methanol combustion to supply the heat for the endothermic steam reforming and fuel evaporation; (c) methanation to reduce the $\mathrm{CO}$ concentration. The reformer contains $14 \mathrm{mg}$ of the $\mathrm{Pd} / \mathrm{ZnO}$ catalyst. $\mathrm{Ru} / \mathrm{Al}_{2} \mathrm{O}_{3}$ was used for the methanation. Fig. 1 shows the steam reforming and the CO-cleanup section of the microprocessor. A similar system has been reported by Holladay et al. [27].

An example for the safe production of phosgene in a MSR is given by Ajmera et al. [16]. The microreactor was fabricated out of single silicon crystalline wafers. The reactor consisted of a $20 \mathrm{~mm}$ long, $625 \mu \mathrm{m}$ wide and $300 \mu \mathrm{m}$ deep reaction channel capped with Pyrex glass. At the outlet of the microchannels a filter with $25 \mu \mathrm{m}$ holes was placed to retain the catalyst powder. Experiments were carried out with ca. $1.3 \mathrm{mg}$ activated carbon with a particle diameter of 53-73 $\mu \mathrm{m}$. The reactor was operated with a stoichiometric mixture of $\mathrm{CO}$ and $\mathrm{Cl}_{2}$ at a total flow rate of $4.5 \mathrm{~cm}^{3} / \mathrm{min}$ (STP). At atmospheric pressure and a temperature of $200{ }^{\circ} \mathrm{C}$ complete conversion was achieved, corresponding to a productivity of $0.4 \mathrm{~g} / \mathrm{h}(3.5 \mathrm{~kg} / \mathrm{a})$ phosgene from a single channel.

\subsection{Catalytic wall reactors}

To avoid high-pressure drop in randomly packed microstructured reactors multichannel reactors with catalytically active walls were proposed. Typical channel diameters are in the range of $50-1000 \mu \mathrm{m}$ with a length between 20 and $100 \mathrm{~mm}$. Up to 10,000 channels are assembled in one unit. Due to the small channel diameters the reactor operates under laminar flow conditions. At low-pressure differences in the channels, the well known Darcy-Weissbach relation can be used for the estimation of the pressure drop [28]. At higher-pressure differences the compressibility of the gas cannot be neglected

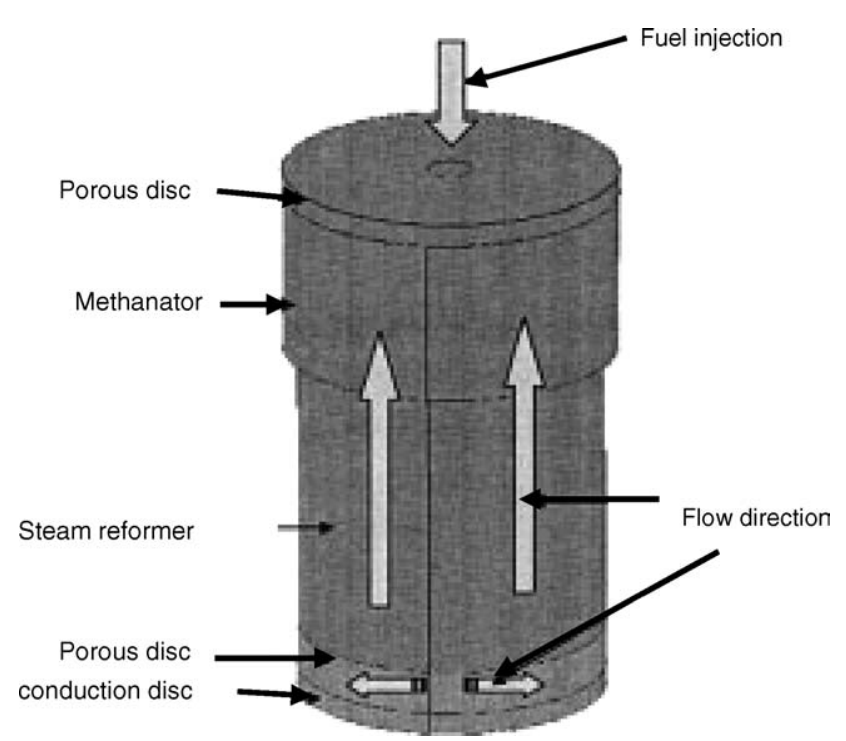

Fig. 1. Integrated methanol steam reformer and CO clean-up section in a micropower fuel processor [26]. 
and the integrated Darcy-Weissbach equation must be used [29].

Besides the kinetic parameters, the mean residence time and the residence time distribution (RTD) in the reactor influence strongly the product yield and selectivity. To get the maximal yield of the intermediate product for consecutive reactions, the RTD in the reactor should be narrow. Microchannel reactors usually work under laminar flow conditions. Therefore, the axial dispersion in the channels can be predicted by the Taylor and Aris relation (Eq. (2)) [30]. For circular tubes the axial dispersion coefficient, $D_{\mathrm{ax}}$, is given by:

$D_{\mathrm{ax}}=D+\frac{d_{\mathrm{t}}^{2} u^{2}}{192 D}$

where $D$ is the molecular diffusion coefficient, $u$ the average linear velocity, and $d_{\mathrm{t}}$ is the tube diameter.

Due to the small tube diameters of the microchannels, the radial diffusion time of gases is in the order of milliseconds and the axial dispersion can be efficiently suppressed, as shown by recent theoretical and experimental studies [31,32]. The optimal design for flow uniformity in microchannel reactors was discussed in detail by Matlosz and co-workers [33]. Delsman et al. [34] used 3D fluid dynamics simulations for optimizing the geometry of the flow distribution chamber in front of the microchannels. Besides RTD, the non-uniform distribution of the catalytic active components in the catalytic layer influences the performance of microchannel reactors. This was demonstrated experimentally and explained theoretically by Platzer et al. [35].

In general, the geometric surface of the microchannels is not sufficient for performing catalytic reactions. Therefore, it is necessary to increase the specific surface area by chemical treatment of the channel walls or by applying reasonably thick porous coatings. The porous layer formed can be catalytically active or serve as a support for a catalytic phase. Different techniques were developed and tested for this purpose over the last years. They will be summarized as follows.

Ganley et al. [36] presented an extensive study on the operational parameters influencing the anodic oxidation of aluminium alloy to create a porous layer of alumina in microchannels. The basic process involves direct current anodization of aluminum in oxalic acid. Electrolyte concentration, temperature, and anodization potential are optimized with respect to the oxidation efficiency and pore density. In addition the effects of subsequent hydrothermal-thermal treatment on the surface area enhancement and morphology of the porous oxide were investigated and optimized (Fig. 2). The study was based on the pioneering work of Hönicke and co-workers [3739]. The obtained oxide layer had regular pore structure oriented perpendicularly to the flow direction. This porous layer served as support for the catalytically active components. A recent example is the use of $\mathrm{Pt}$ supported on nano-porous alumina obtained by anodic oxidation and its integration into a microcatalytic combustor [40].

A successful method to create a thin porous alumina layer on a steel substrate is based on the high temperature treatment of Al containing steel (e.g. DIN 1.4767, "FeCr Alloy"). This alloy is commonly used as construction material for metallic monoliths applied in automotive exhaust converters. By heating the alloy for approximately $5 \mathrm{~h}$ at $1000{ }^{\circ} \mathrm{C}$ a thin alumina film of ca. Five micrometers is formed on the steel surface [41]. This $\mathrm{Al}_{2} \mathrm{O}_{3}$ film can be used as support for catalytically active metals as shown by Aartun et al. [42]. The porous alumina layer formed on the surface of the channels were impregnated with $\mathrm{Rh}$. The reactor was tested for partial oxidation (POX) and oxidative steam reforming (OSR) of propane at $0.1 \mathrm{MPa}$ and in the temperature range $500-1000{ }^{\circ} \mathrm{C}$. The results were compared to those obtained from equivalent experiments using reactors made of pure $\mathrm{Rh}$ or from oxidized $\mathrm{FeCr}$ alloy reactors without catalyst or with supported Ni. OSR gave higher yields of hydrogen than POX for the $\mathrm{Rh} / \mathrm{Al}_{2} \mathrm{O}_{3} /$ $\mathrm{FeCr}$ alloy system. The $\mathrm{Rh} / \mathrm{Al}_{2} \mathrm{O}_{3} / \mathrm{FeCr}$ alloy reactor gave higher selectivities to hydrogen as compared to the reactor made of $\mathrm{Rh}$, indicating that high catalyst dispersion on a porous layer in the microchannels is beneficial. Deactivation due to coke formation was not observed for the $\mathrm{Rh} / \mathrm{Al}_{2} \mathrm{O}_{3} / \mathrm{FeCr}$ alloy system under the conditions applied. Wang et al. [43] used the alumina layer formed on $\mathrm{FeCr}$ alloy to increase the adherence of a $\mathrm{MgO} / \mathrm{Al}_{2} \mathrm{O}_{3}$ layer introduced by washcoating with supported Rh. This catalyst was highly active for steam reforming of methane and resistant to coke formation at the stoichiometric steam $/ \mathrm{CH}_{4}$ ratio. Methane steam reforming activities on this catalyst were compared in both a microchannel reactor and a conventional microtubular reactor. Significant performance enhancement was observed in microchannel reactors owing to the improved heat and mass transfer.

An interesting approach was reported by Reuse et al. $[44,45]$. The authors developed a wash-coating method for the

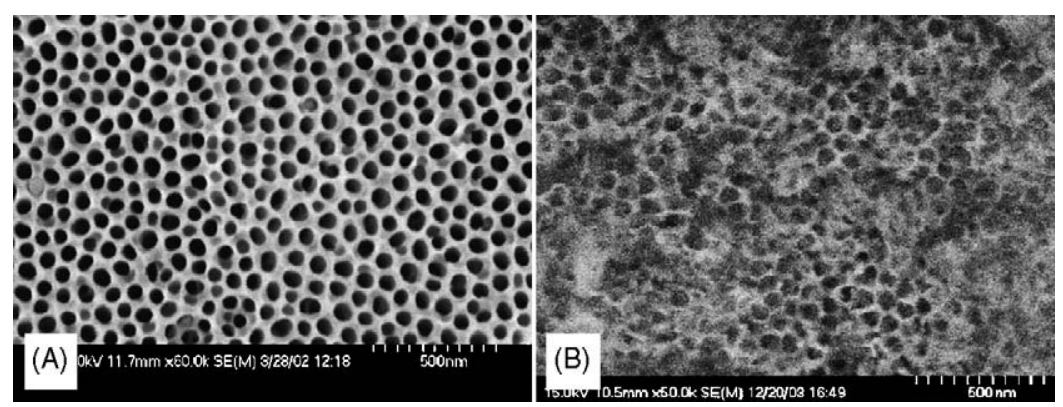

Fig. 2. Surface morphology of anodized microreactors (A) without, (B) after hydrothermal treatment [36] 
direct use of commercially available catalysts for the steam reforming of methanol. The copper based catalyst (G-66MR, Südchemie) was micromilled to particles in the nanometer range and used for the coating of the microchannels. The activity of the catalyst layer was found to exceed the values of the original formulation. The observation may be explained by a mechanical activation of the catalyst $[46,47]$. The method proposed allows shortening of the tedious and time consuming procedure for the development of an active catalytic layer. Similar methods were applied by Bravo et al. [48] and Park et al. [49,50] for the catalytic steam reforming in microchannels.

As methanol steam reforming is an endothermic reaction, it is necessary to provide the reactor with sufficient heat. The use of microstructured reactors to bring heat directly to the core of the reactor by coupling the endothermic reforming with an exothermic combustion was applied by Reuse et al. [45]. For this purpose, the off-gas of the fuel cell containing not converted hydrogen and methanol was burned (Eq. (3)) supplying the heat for the steam reforming of methanol.

$$
\begin{gathered}
\mathrm{CH}_{3} \mathrm{OH}+3 / 2 \mathrm{O}_{2} \rightarrow \mathrm{CO}_{2}+2 \mathrm{H}_{2} \mathrm{O} ; \\
\Delta_{\mathrm{r}} H^{250^{\circ} \mathrm{C}}=-673.2 \mathrm{~kJ} \mathrm{~mol}^{-1}
\end{gathered}
$$

The catalyst for total oxidation must be highly active in the temperature range used for the steam reforming to achieve complete conversion of methanol. Therefore, synchronization of the minimal temperature for total oxidation with the maximal temperature of the steam reforming to ensure an acceptable catalyst lifetime has to be realized. For the coupled methanol steam reforming/total oxidation a two passage MSR was developed. The reactor consists of staked plates (Fig. 3A) and could be used in the co-current or counter-current mode (Fig. 3B). The plates were $78 \mathrm{~mm}$ long, $23 \mathrm{~mm}$ large and $200 \mu \mathrm{m}$ thick. The channels are "S" shaped: 17 rounded channels are split up to give 34 straight channels with a total length of $30 \mathrm{~mm}$ long. They were $320 \mu \mathrm{m}$ large and $100 \mu \mathrm{m}$ deep. Only the straight part was used for the reactions. The plates for the second reaction are the mirror image of the first one. All plates are staked together in the housing (Fig. 3B). In the middle of the stack a special plate, designed for temperature measurements, is inserted. A top plate is screwed in the housing to close the reactor hermetically.

As the copper zinc oxide catalyst was found to be not active enough for complete oxidation of methanol in the temperature range of steam reforming, a cobalt oxide catalyst was developed to coat the plates dedicated to catalytic combustion of methanol. An aqueous solution of cobalt nitrate was introduced into the channels, dried and activated by calcination for $2 \mathrm{~h}$ at $350{ }^{\circ} \mathrm{C}$ [51]. The catalytic plates contained each $22 \mathrm{mg}$ of cobalt oxide.

Another promising method to obtain oxide layers onto the walls of microchannels is the sol-gel technology. It has the advantage of producing a wide variety of compositions, tailored
(A)
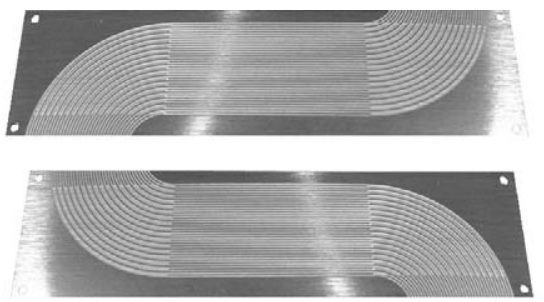

(B)

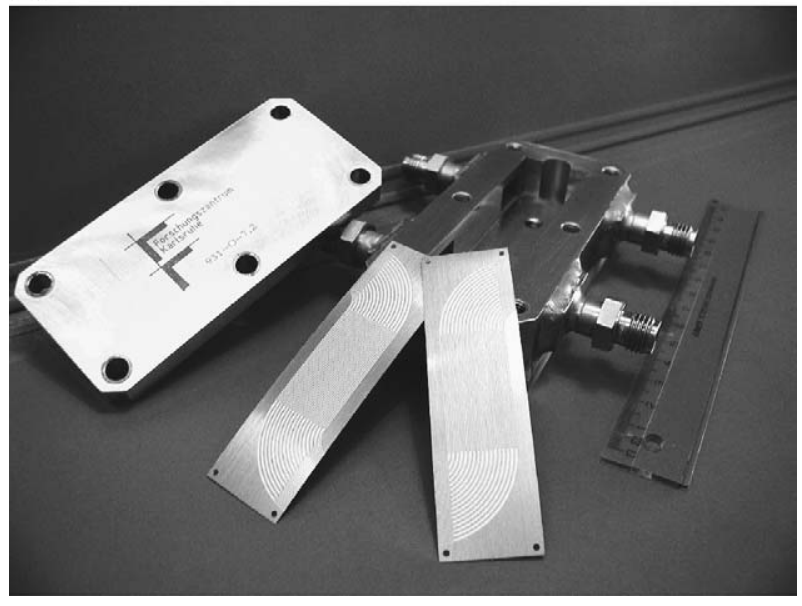

Fig. 3. Autothermal microchannel reactor. (A) microstructured plates, (B) housing of the two passage microstructured reactor [45].

porosities and surface textures. These properties can be controlled by varying the composition and treatment procedure of the sol [52]. Lim et al. [53] used the sol-gel technique to coat the microchannels with a $\mathrm{Cu} / \mathrm{ZnO} / \mathrm{Al}_{2} \mathrm{O}_{3}$ catalyst for methanol steam reforming. For this purpose they used a zirconia-sol. Zirconia is a ceramic material with excellent adhesive properties.

Compared to conventional packed beds, zeolite coated microchannel reactors demonstrate higher productivity per mass of catalyst [54]. This can be explained by the fact that if the channels in a MSR are coated with a $1-2 \mu \mathrm{m}$ layer of zeolite, almost all catalyst is available for the reaction at much lower pressure drop compared to a fixed bed of zeolites with the same particle size. In addition, the large surface to volume ratio of zeolite-coated microchannels provides an excellent contact between reactants and catalyst, thus minimizing bypass. This was demonstrated by Hiemer et al. [55] for the hydroxylation of benzene with $\mathrm{N}_{2} \mathrm{O}$ over Fe-ZSM- 5 coated stainless-steel MSR. The authors describe a slurry coating technique using aluminium oxide as a binder and glacial acetic acid as the peptising agent. They investigated the influence of the binder on the zeolite-layer properties such as surface area, micropore volume and adhesive strength. The MSR allowed working at high temperatures and concentrations of reactants, thus achieving high space-time yields. An elegant way to prepare catalytically active microreactors is by applying a direct coating of zeolite crystals onto a metal microchannel structure. Rebrov et al. [56] studied the hydrothermal formation of ZSM5 zeolitic coatings on AISI 316 stainless steel plates with a microchannel structure at different synthesis mixture compositions. The prepared samples proved to be active in the selective catalytic reduction (SCR) of NO with ammonia. The 
microreactor shows no mass transfer limitations and a higher SCR reaction rate is observed compared to pelletized ZSM-5 catalysts.

The chemical vapor deposition (CVD) process is a valuable tool for obtaining porous ceramic coatings on the inner walls of a microchannel system. Janicke et al. [57] deposited an alumina layer within microchannels and obtained an enhancement of the specific surface of a factor -100 .

Thin nano-structured films of $\mathrm{Mo}_{2} \mathrm{C}$ were grown on $\mathrm{Si}\left(\begin{array}{lll}1 & 0 & 0\end{array}\right)$ by metal-organic chemical vapor deposition by Chen et al. [58] using $\mathrm{MO}(\mathrm{CO})_{6}$ as precursor. The formation of benzene from methane over the nano-structured films has been observed in the studies confirming that $\mathrm{Mo}_{2} \mathrm{C}$ and $\mathrm{MoO}_{3}$ are the active catalysts for methane aromatization.

Small nanoparticles of metal oxides can be generated by flame combustion of volatile precursors. The so-called flame combustion synthesis, widely used for materials like carbon black, fumed silica, and titania provides an alternative route of the catalyst manufacture as demonstrated recently [59-61]. Thybo et al. [62] investigated a flame spray technique as a method for one-step synthesis and deposition of porous catalysts onto surfaces and into MSR. Fig. 4 shows the mounting of a microreactor in the flame spray set up. A shadow mask is used to cover everything except the reactor channel during exposition. Only very small amounts of catalyst enter the inlet and outlet channels due to Brownian motion. After deposition, the surface of the reactor is sufficiently clean for anodic or adhesive bonding. Fig. 5 shows a microchannel loaded with $\mathrm{Au} / \mathrm{TiO}_{2}$ porous catalyst.

The presented coating techniques lead to metal oxide coatings. Techniques to produce carbon-based coatings in microstructures are much less investigated. This is astonishing since carbon is a common support in catalysis with a broad variety of applications. An exception is the study of Schimpf et al. [63] exploring the potential of carbon-coated microstructures for heterogeneously catalyzed hydrogenations. Carbon-coated microstructures have been prepared via carbonization of polymers, which have been deposited onto microstructured wafers of a

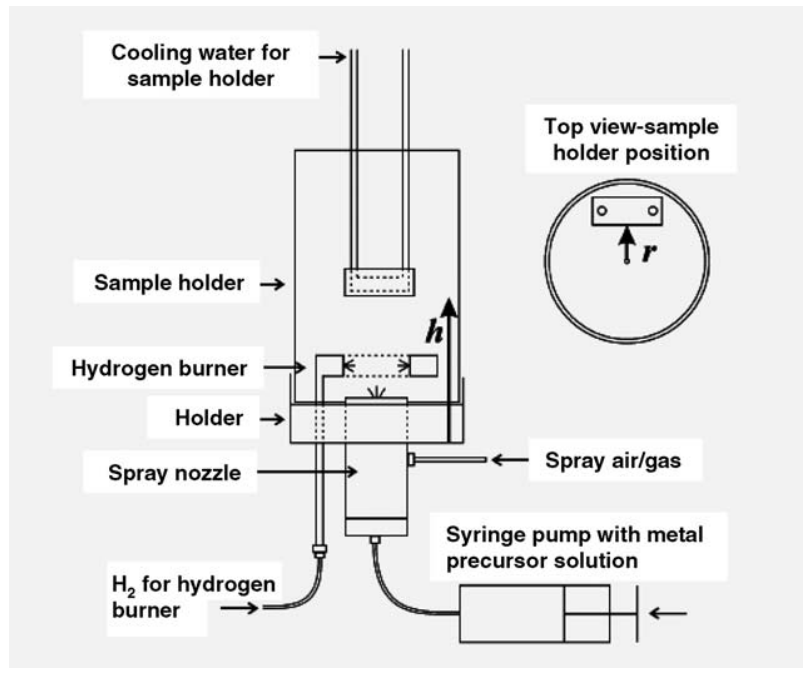

Fig. 4. Experimental set up for the flame spray deposition of porous catalyst on substrate surfaces [62].

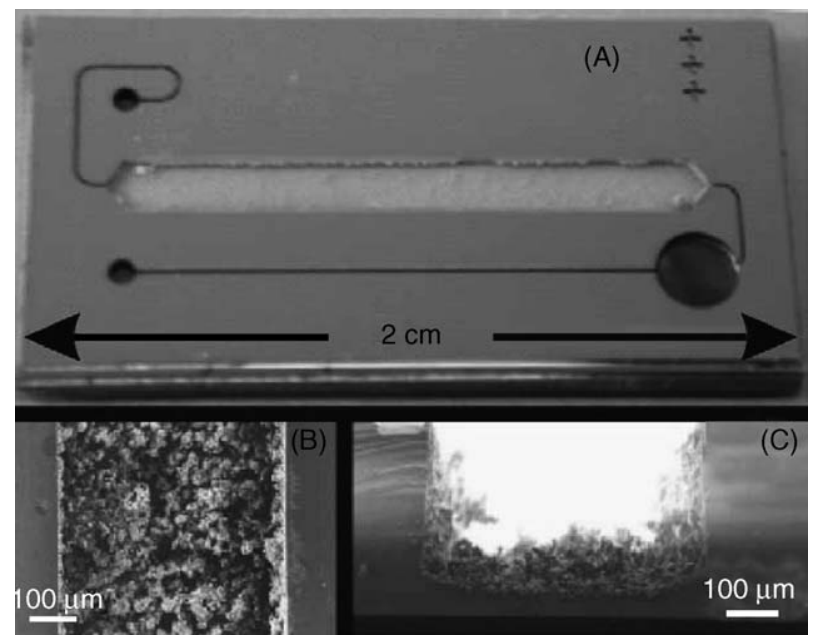

Fig. 5. Photograph of the sample holder with a microreactor after flame spray deposition of the catalyst [62].

$\mathrm{MgAl}$ alloy. The amount of carbon deposited depends on the composition of the precursor monomer solution and on the presence of a template. The activity and selectivity of the wafers after loading with ruthenium in the hydrogenation of acrolein was affected by the composition of the polymers and the time of the calcination step. The authors explain the observations by the carbon surface functional groups as well as the porosity of the carbonaceous layer.

Microstructured reactors made of metals or polymers are not suitable for chemical reactions at high temperatures or/and with corrosive reactants involved. Ceramic materials are a valuable alternative for this kind of application. Knitter and Liauw [64] developed a modular microreactor system made of alumina fabricated by a rapid prototyping process. With exchangeable inserts, the system can be adapted to the requirements of various reactions (Fig. 6). Two heterogeneously catalysed gasphase reactions, oxidative coupling of methane and isoprene selective oxidation to citraconic anhydride, were investigated confirming the system suitability at temperatures up to $1000{ }^{\circ} \mathrm{C}$. Apart from the high thermal and chemical resistance, the absence of any blind activity was found to be another advantage of ceramic components.

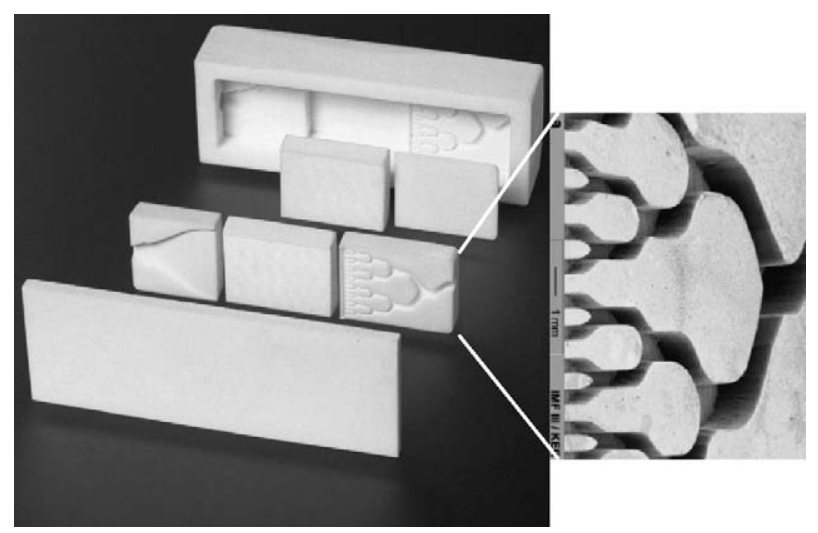

Fig. 6. Ceramic microreactor with exchangeable functional elements [64]. 

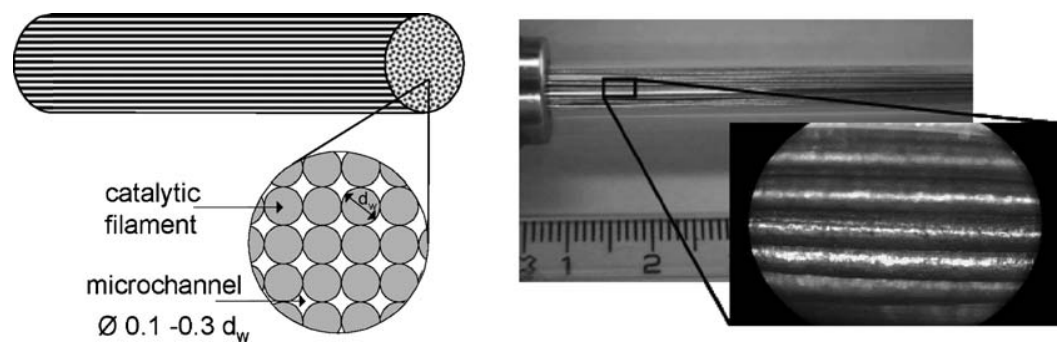

Fig. 7. Schematic presentation and photograph of the microstructured string reactor [69].

\subsection{Novel designs of MSR}

The drawback of randomly packed microchannels by catalyst is the high-pressure drop. In addition, each channel must be packed identically to avoid maldistribution, which is known to lead to a broad residence time distribution (RTD) during the passage of the reactants through the reactor. To avoid problems related to the use of randomly packed beds, structured catalytic beds were recently proposed [65-69]. The novel concept was applied for the MSR containing a structured catalytic bed arranged with parallel filaments or wires. This micro "string reactor" gives flow hydrodynamics similar to multi-channel microreactors. The channels for gas flow between the filaments have an equivalent hydraulic diameter in the range of few microns ensuring laminar flow and short diffusion times in the radial direction leading to a narrow RTD. The novel MSR was applied for the oxidative steam reforming of methanol (OSRM) $[68,69]$. OSRM is based on the combination of the exothermic oxidation and endothermic reforming in the same reactor. At $300{ }^{\circ} \mathrm{C}$ a formally athermic reaction occurs for the following composition of the reactant feed:

$$
\begin{aligned}
& 4 \mathrm{CH}_{3} \mathrm{OH}+3 \mathrm{H}_{2} \mathrm{O}+0.5 \mathrm{O}_{2} \rightarrow 4 \mathrm{CO}_{2}+11 \mathrm{H}_{2} \\
& \Delta_{\mathrm{r}} H^{573} \cong 0 \mathrm{~kJ} \mathrm{~mol}^{-1}
\end{aligned}
$$

Reactors in this case operate autothermally, i.e. do not require any external heating or cooling once having reached the reaction temperature. The main difficulty in carrying out the OSRM is due to the much faster methanol oxidation compared to the reforming rate. As a consequence, heat is generated mostly at the reactor entrance, whereas, the heat consumption occurs in the middle and rear of the reactor. In conventional reactors with randomly packed beds and low axial and radial heat conductivity, pronounced axial temperature profiles are developed [70]. They are characterized by hot spot at the reactor entrance and a "cold spot" in the second part of the reactor [71]. The high temperature may damage the catalyst and the low temperature diminishes the rate of the reforming reaction leading to poor reactor performance. Thus the temperature control is crucial for the reactor performance.

To avoid axial temperature profiles the catalyst in the form of thin metallic wires with diameters in the millimeter range was introduced into "macro" tubular reactor (Fig. 7). This design provides laminar flow with narrow RTD and low-pressure drop throughout the catalytic bed [67]. Brass wires with high heat conductivity $(120 \mathrm{~W} /(\mathrm{m} \mathrm{K}))$ are chosen for the microstructured string reactor as they contain $\mathrm{Cu}$ and $\mathrm{Zn}$ catalyzing the reforming/oxidation of methanol. To obtain metal wires with high specific surface area a thin metal/aluminium alloy is formed on the wire outer surface [72]. The aluminium is leached out either by acid or by basic boiling solution resulting a thin porous layer with a morphology similar to that of Raney metals. In the OSRM the microstructured string reactor showed high selectivity for $\mathrm{CO}_{2}$ and $\mathrm{H}_{2}(\geq 98 \%)$. Hot and cold spots in the reactor were efficiently reduced down to $\Delta T<1.5 \mathrm{~K}$ at methanol conversions $X>50 \%$ [73].

Besides metallic wires, metallic grids may be used for microstructuring catalytic reactors. They provide a uniform gas distribution and reduce the risk of excessive temperature gradients in the reactor. The specific surface can be increased by the formation of a highly porous Raney metal layer on the metal as described above. Surface enhancement factors of up to 20000 could be obtained [51]. An example for a developed surface on Ni-wires is shown in Fig. 8. The developed surface

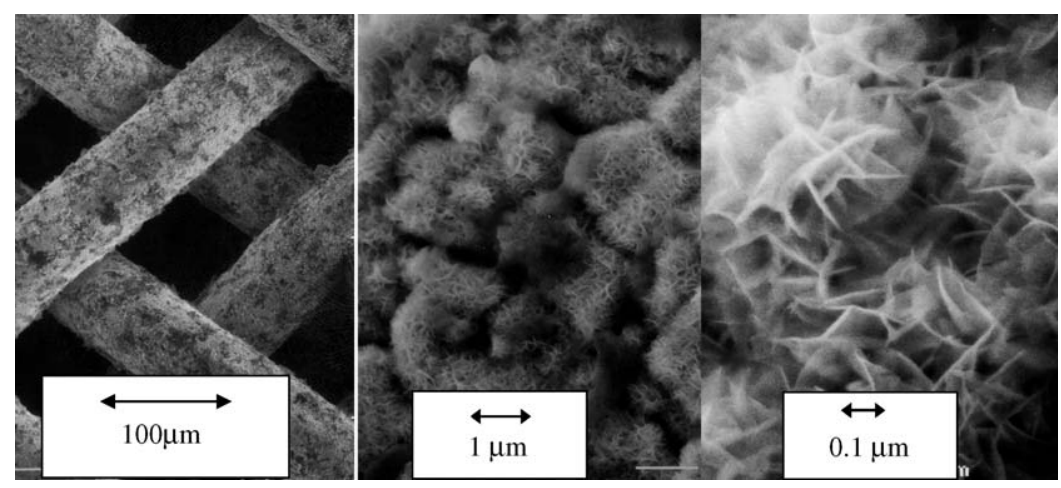

Fig. 8. SEM images of the Ni-grid catalyst with Raneytype outer surface at different magnifications $[75,77]$. 
can be used as support for active phase depending on the reaction to be carried out. Examples for the successful application of microstructured catalysts based on metallic grids are the catalytic combustion of volatile organic compounds (VOC) $([51,74])$ and the hydrogen production by catalytic cracking of methane [75-77].

The metallic grids used in the studies reported above were made of wires with a diameter of ca. $0.1 \mathrm{~mm}$ with meshes in the same order of magnitude. The openings can be significantly reduced by using metallic fiber filters. Sintered metal fiber filters (SMF) have uniform micron sized filaments sintered into a homogeneous 3D structure. SMF present porosities of 80 $90 \%$, and in high permeability. Fibers made of alloys (stainless steel, Inconel, $\mathrm{FeCr}$ alloy) exhibit high mechanical strength, chemical and thermal stability. High thermal conductivity of the metal fiber matrix provides an efficient radial heat transfer, and act also as a static micromixer. These are advantageous for their use as building units in microstructured reactors. Yuranov et al. produced a thin uniform zeolite film with controlled thickness coating the metal microfibers [78]. The coating consisted of highly intergrown crystals about $1 \mu \mathrm{m}$ in size with prismatic MFI morphology. The zeolite/SMF elements can be assembled in the form of disks presenting a three level catalyst structure: (a) nano-structure of the zeolite film, (b) microstructure of the porous 3D media of sintered metal fibers and (c) macrostructure of the layered catalytic bed formed from the composite elements (Fig. 9).

As demonstrated in the above-mentioned study, temperature gradients within the reactor can be efficiently reduced by using highly thermal conducting materials, like copper or brass, as catalyst support [79]. To avoid the subsequent coating of the structured metal Schuessler et al. [80] proposed to add copper particles to the $\mathrm{Cu} / \mathrm{ZnO} / \mathrm{Al}_{2} \mathrm{O}_{3}$ powder catalyst, commonly used for methanol reforming. Copper was chosen as matrix building material because of its high heat conductivity ( $402 \mathrm{~W} /$ $(\mathrm{m} \mathrm{K}))$ and low melting point $\left(1083^{\circ} \mathrm{C}\right)$. The low melting point allows to join the copper particles by sintering at moderate temperatures of $500-700{ }^{\circ} \mathrm{C}$.

Novel catalysts structures with microchannels able to reduce the diffusion resistance in fast heterogeneous gas phase reactions were developed by Bae et al. [81]. They fabricated

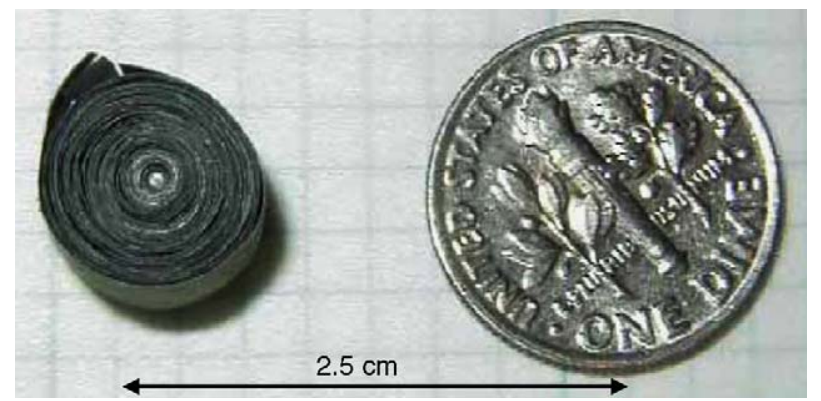

Fig. 10. Microchannel catalyst for autothermal reforming of hydrocarbon fuels [81].

a structured microchannel catalyst by means of a modified ceramic tape casting process. Catalyst powders, containing Gd-doped $\mathrm{CeO}_{2}$ with $\mathrm{Pt}(0.5$ wt. \%) were dispersed by means of the commercial dispersion agents and solvents like xylenes and alcohols. The catalyst slurry was mixed with organic binder such as polyvinylbutyral or acryloid. The final slurry was casted at the desirable thickness of 50-200 $\mu \mathrm{m}$ and subsequently dried in air. Fugitive materials like organic fabric can be inserted and the tape retains the slurry phase to leave holes, or thin fugitive materials $(1-50 \mu \mathrm{m})$ can be added on top of the fully dried catalyst tape to leave space after the burning process.

The dried catalyst tape maintained its flexibility due to the plasticity of the organic binder and enabled further mechanical treatment such as cutting and rolling. The tape was cut into strips of about $1 \mathrm{~cm}$ width and rolled into a 'jellyroll' shape of the selected diameter. A small-size microchannel catalyst of about $1 \mathrm{~cm}$ diameter prepared for microreactor tests is shown in Fig. 10. The microchannel was loaded inside a stainless-steel microreactor tube and heat-treated to burn the fugitive layer away and sinter the catalyst powder as a self-supported form. After burning of the fugitive layer, well-defined channels were created. The microchannel reforming catalysts were tested with natural gas and gasoline-type fuels at space velocities of up to $250,000 \mathrm{~h}^{-1}$. The catalysts have also been used in engineering-scale reactors $\left(10 \mathrm{~kW}_{\mathrm{e}}\right.$; diameter of $\left.7 \mathrm{~cm}\right)$ with similar product qualities. Compared with pellet catalysts, the microchannel catalysts offer a nearly five-fold reduction in catalyst weight and volume.

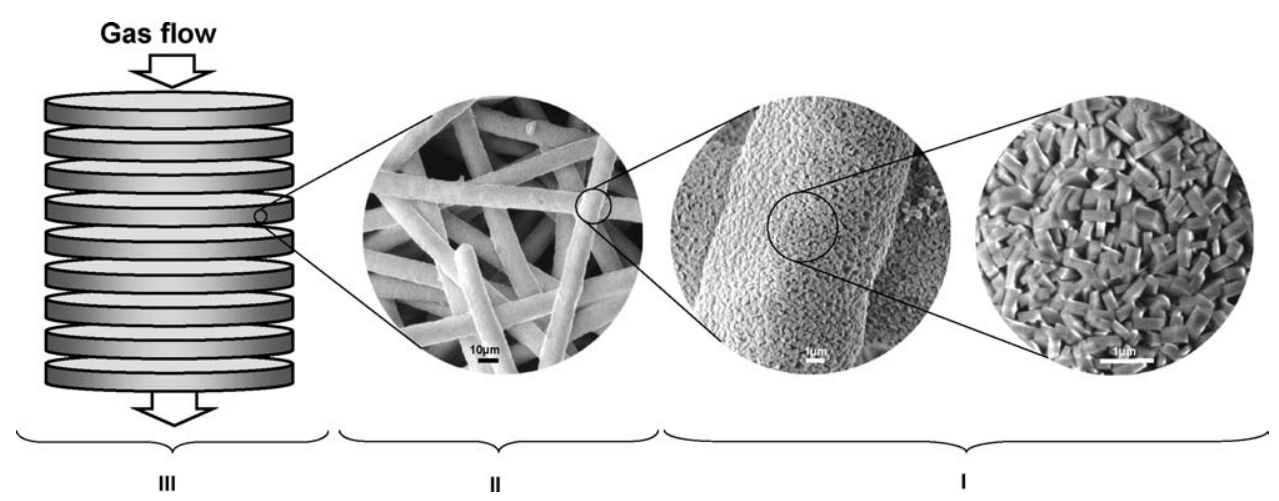

Fig. 9. Three-level structure of the zeolite/sintered metal fiber structured catalytic bed: (I) microstructure of the zeolite film of oriented submicron crystals; (II) mesostructure of the porous sintered metal fiber layer; (III) structure of the layered catalytic bed [78]. 
The small volume and weight of microreactors lead to short transient periods after the start up or after a change in the reaction conditions. Microreactors allow fast heating and cooling of the reaction mixture within fractions of seconds $[9,82]$. Therefore, reactions can be carried out under defined short reaction times avoiding parallel and consecutive reactions. An example is the catalytic dehydrogenation of methanol to water-free formaldehyde. The reaction takes place in the range of 1000-1200 K attaining complete conversion of methanol within milliseconds. Formaldehyde is unstable under the reaction conditions and decomposes to carbon monoxide and hydrogen. This is why the reaction mixture has to be quenched rapidly at the reactor outlet. When using a microstructured heat exchanger, the temperature gradients of up to $6400 \mathrm{~K} / \mathrm{s}$ were attained for freezing the reaction mixture and leading to formaldehyde yields of more than $80 \%$ at nearly complete conversion of methanol [83].

The excellent dynamic behavior of microreactors can be exploited for running the reactions under non steady state conditions by changing periodically concentration and/or temperature. Periodic operation of catalytic chemical reaction may lead to increased reactor performance, improved selectivity, and reduced catalyst deactivation compared to the reaction performed under steady state conditions [84]. The advantages of fast periodic concentration oscillations in microreactors was reported by Rouge et al. [31,85].

Recently, microstructure devices for "fast temperature cycling" have been also described [86,87]. The devices allowed to obtain a periodic temperature change of $100 \mathrm{~K}$ within less than a second. The oxidation of carbon monoxide was chosen as model reaction. Under fast temperature cycling, a considerably higher $\mathrm{CO}_{2}$ yield compared to the steady state value was obtained.

\section{MSR for catalytic multiphase systems}

In multiphase reactions containing liquids, mixing of the reactants and the interfacial mass transfer is of primary importance. The laminar flow prevails in microreactors and the diffusion coefficients in liquids are four orders of magnitude smaller compared to gases. This is why mixing is an important issue for the effective reactor performance. Passive and active mixing useful in the design of micromixers are described in detail in a recent review of Hessel et al. [88], whereas Doku et al. [89] reviewed microreactor designs for multiphase contacting. In the following chapters we will report on MSR for (a) liquid-phase reactions with homogeneous catalysts, (b) liquid-phase reactions with solid catalyst and (c) multiphase (gas-solid-liquid) catalytic reactions.

\subsection{MSR for homogeneous catalytic liquid reactions}

In the chemical industry numerous reactions are carried out on a large scale, which are strongly exothermic and involve two liquid phases [90]. In general, the reaction occurs in only one of the phases, but the mass transfer between the two immiscible liquids and chemical reaction are intimately linked. A precise determination of the individual steps under well-defined isothermal conditions is essential for the optimal design of the chemical reactor. Dummann et al. [91] choose the highly exothermic nitration of an aromatic ring as test reaction. Nitrations are of industrial importance. The homogeneously catalyzed reaction takes place in the aqueous phase, which consists of a mixture of concentrated sulfuric and nitricphosphan acids. The authors developed a capillary-microreactor for their studies. In the capillary-microreactor, isothermal behavior was assumed due to the high heat transfer rates. In addition, a liquid-liquid two-phase plug-flow with a welldefined flow pattern of alternating plugs of the two phases is formed, giving a constant, uniform specific surface area for mass transfer between the two phases (Fig. 11). In the nitration reaction, not only the mononitrated product is formed, but also by-products via consecutive and parallel reactions. Therefore, interfacial mass transfer and residence time distribution in the reactor strongly influence the product yield and selectivity. The capillary microreactor was shown to behave like a plug flow reactor allowing a high mass transfer between the phases.

The nitration of organic compounds in a microreactor was also studied by Antes et al. [92]. The aim of the study was to develop on-line analytical techniques. Fast and quantitative determination of reaction products is essential to determine a reaction mechanism and a kinetic model. To avoid consecutive reactions, fast quenching of the reaction mixture and phase separation is essential. For the nitration of toluene with fuming nitrous acid (without sulphuric acid) mononitrotoluene yields of $89-92 \%$ were obtained at a space-time of $3 \mathrm{~s}$ and a reactor wall temperature of $-10{ }^{\circ} \mathrm{C}$. In addition, the selectivity for the para-substituted product was significantly increased $(43.5 \%)$ compared to selectivity reported for the industrial process (33\%). The higher para-selectivity can be explained by the enlarged boundary between organic and aqueous phases.

To get reliable kinetic data for fast exothermic liquid phase reaction Schneider et al. [93] developed a new system combining a microreactor with a microcalorimetric chip. The small sizes of the microreactor channels permit maintaining isothermal conditions necessary for the kinetic characterization of highly exothermic reactions. Usually this is not easy to obtain in classical calorimetric systems. As fast mixing in the microchannels plays an important role for the characterization of fast reactions, the authors determined the micromixing characteristics using an iodate-iodide system.

Jönsson et al. [94] used a T-shaped MSR for the optimization of the reaction conditions for the enantioselective silyleyanation of benzaldehyde catalyzed by lanthanide-pybox complexes. Compared to a conventional batch procedure, higher conversion was observed within shorter reaction time. The

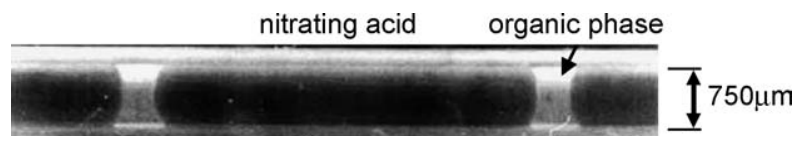

Fig. 11. Liquid-liquid two-phase plug-flow with plugs of nitrating acid and organic phase in a capillary microreactor [91]. 


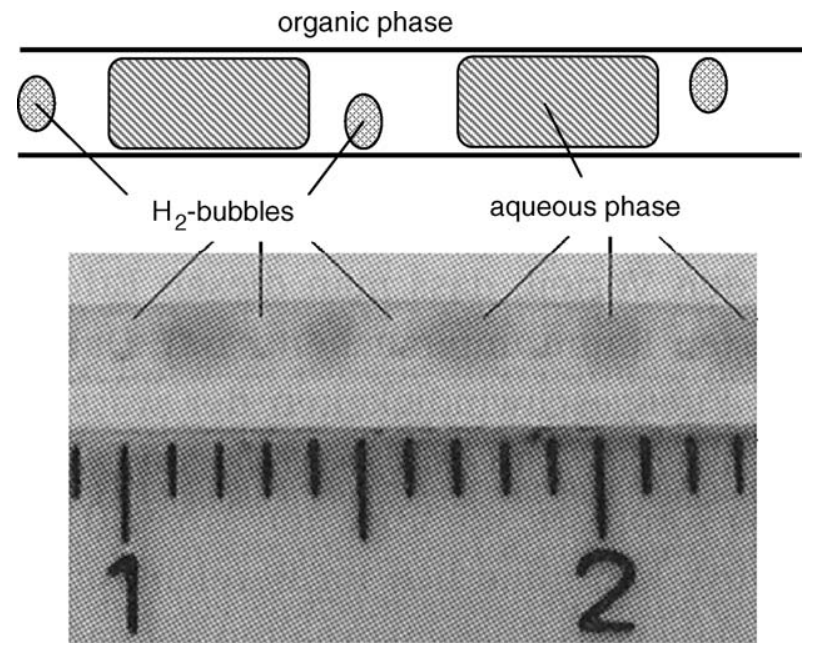

Fig. 12. Fluid-dynamic behavior of a three-phase gas-liquid-liquid capillary microreactor (scheme and photograph) [95].

microreactor process afforded almost the same enantioselectivity as the batch process (73\%e.e. versus $76 \%$ e.e.).

A single capillary PTFE microreactor for the selective hydrogenation of $\alpha, \beta$-unsaturated aldehydes in aqueous solution was presented by Önal et al. [95]. The catalyst $\mathrm{Ru}(\mathrm{II})$-TPPTS (triphenylphosphantrisulfonat-sodium) was dissolved in the aqueous phase, and therefore was physically separated from the reactant and product in the organic phase. Hydrogen was used as a reducing agent. The authors observed plug flow of alternating organic and aqueous slugs with gas bubbles in the organic phase as shown in Fig. 12. The overall reaction rate was observed strongly dependent on liquid/liquid mass transfer. By decreasing the diameter of the capillary the specific surface and the internal recirculation in the organic phase increases leading to a better volumetric mass transfer. For the present example, a three-fold increase of the global reaction rate was observed by reducing the channel diameter from 1000 to $500 \mu \mathrm{m}$.

Finally, microstructured reactors are useful tools for studying and screening homogeneous liquid catalysts. This has been shown during the development of water-soluble catalysts for the liquid/liquid isomerization of allylic alcohols [96].

\subsection{MSR for catalytic solid-liquid reactions}

The use of heterogeneous catalysts facilitates the catalyst recycling and reuse. The main drawbacks are eventual heat and mass transfer limitations, which are known to influence selectivity and yield in complex reactions. As MSR offer high specific surfaces, the influence of transfer phenomena on the overall reaction can be reduced partially or completely.

A Pyrex glass capillary (400 $\mu \mathrm{m}$ internal diameter) MSR was developed and used for the Suzuki coupling reactions by Basheer and co-workers [97]. A scheme of their device is shown in Fig. 13. Palladium nanoparticles prepared from Pdacetate were efficient catalysts. In the capillary microreactor, the reactants mobility was driven by electro osmotic flow,

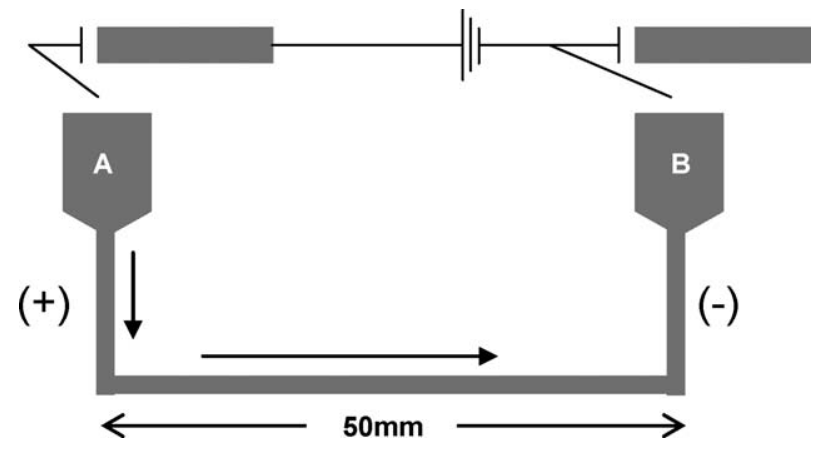

Fig. 13. Schematic diagram of the capillary microreactor for SUZUKI coupling reactions [97].

which was controlled by the applied potential. Compared with conventional synthesis procedures, the capillary microreactor offers a convenient way to optimize the catalyst performance. The procedure described above exhibits good precision, reproducibility and high reaction yield for the different reactants investigated.

A similar reactor design was used for the oxidation of glucose to gluconic acid [98]. A porous gold(0) sponge was used as catalyst.

Zeolites can be deposited and grown on silicon and glass substrates by hydrothermal synthesis [99,100]. Wan et al. [101] coated the walls of silicon-glass microreactors with titanium silicalite-1 (TS-1) for 1-pentene epoxidation with hydrogen peroxide in continuous flow. Seeding of the microchannels before zeolite growth was necessary to obtain a small crystal size and a sufficient zeolite film thickness. The crystal size could be further reduced by adjusting the synthesis conditions and utilizing triethoxymethylsilane (TEMS) as a crystal growth inhibitor. Zeolite film morphology and crystal orientation did not show any significant effect on the reactor performance. However, the reaction rate was found to increase with decreasing TS-1 crystal size in the zeolite films and with an increasing amount of tetrahedrally coordinated Ti(IV).

New basic catalysts obtained by grafting amino groups onto $\mathrm{NaX}$ and $\mathrm{CsNaX}$ zeolites were deposited into microchannels of $300 \mu \mathrm{m}$ wide, $600 \mu \mathrm{m}$ depth, and $25 \mathrm{~mm}$ length. The catalysts exhibited excellent activities for Knoevenagel condensation reaction between benzaldehyde and ethyl cyanoacetate (ECA), ethyl acetoacetate (EAA) and diethyl malonate (DEM). Compared to a traditional packed bed reactor, the $\mathrm{CsNaX}$ zeolite microreactor showed an order of magnitude higher productivity.

A two-step procedure for immobilizing enzymes on the walls of microchannels was developed by Miyazaki et al. [102] using sol-gel procedure to prepare a porous structure on the walls. Subsequently, the enzyme was immobilized through amide-bond formation on the surface. The reactor was used for enzymatic hydrolysis and demonstrated high specific performances.

Brivio et al. [103] observed an interesting effect due to the glass surface of MSR in the esterification of 9-pyrenebutyric acid with ethanol. The reaction was carried out in a borosilicate microchannel (200 $\mu \mathrm{m}$ wide, $100 \mu \mathrm{m}$ deep, $197 \mathrm{~mm}$ long). 
Whereas in conventional glass equipment no esterification could be observed after $40 \mathrm{~min}$, a $15-20 \%$ conversion was obtained in the MSR. The authors explain the results by the catalytic effect of the glass surface, attained due to the high specific surface in MSR.

\subsection{MSR for catalytic three-phase reactions}

The catalyst design and its integration with the design of the reactor for carrying out three-phase reactions are crucial for product selectivity and yield as well as for the reactor performance. The catalyst design should be considered over three main levels: nano-, micro- and macro-scale. The various levels of the catalyst design are not independent and must be considered in an integrated approach in relation to the reactor design [104]. Various factors, like the catalyst characteristics, mass- and heat-transfer limitations, fluid dynamics, flow regimes, and pressure drop must be taken into consideration. This concept is also valid when developing MSR and few examples are given below.

Hydrogenations are important industrially relevant reactions. As they are highly exothermic reactions, an efficient heat transfer is crucial for efficient reactor performance. Besides packed microchannels [105] catalytic wall reactors are used. Normally alternating slugs of two immiscible fluids (liquid/ liquid, or liquid/gas) appear in microchannel reactors [106]. The Taylor flow is formed and guarantees high mass transfer between the different phases. A different design for three-phase system was proposed by Kobayashi et al. [107]. They immobilized $\mathrm{Pd}$ on the glass wall and operated the microchannel reactor in such a manner that the liquid film formed on the wall is separated from the gas-phase in the channel center (Fig. 14). The hydrogenation of benzalacetone was used as a model reaction to proof the general applicability of this concept. The authors could achieve an effective interaction between hydrogen, substrates, and a palladium catalyst due to the large interfacial areas and the short path required for molecular diffusion in the narrow channel space.

Another innovative design for highly exothermic gas/liquid reactions are microstructured falling film reactors. Whereas,

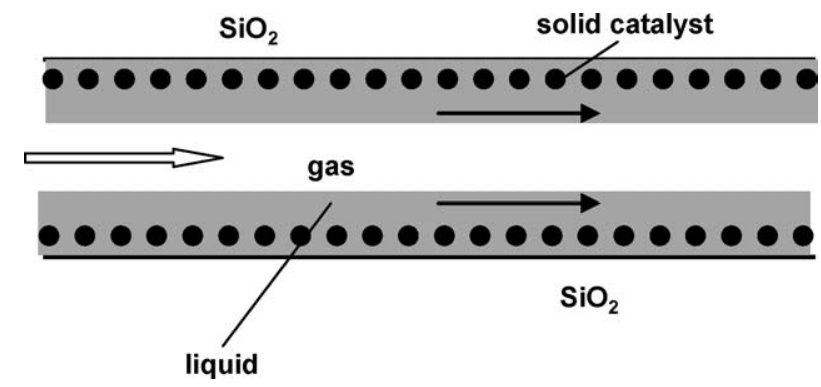

Fig. 14. Device for multiphase reactions (schematic) [107].

conventional falling film systems generate liquid films with a thickness of $0.5-3 \mathrm{~mm}$, the film thickness obtained in the filmMSR is in the $100 \mu \mathrm{m}$ range (Fig. 15) [108]. Therefore, the film-MSR offers excellent heat and mass transfer capabilities. This was proven with the hydrogenation of nitrobenzene [108] and the hydrogenation of cyclohexene [109]. In both cases alumina was deposited on the wall by washcoating with subsequent Pd deposition by impregnation.

An important parameter for the reactor performance in gas/ liquid/solid systems concerns the gas/liquid mass transfer. Yeong et al. used confocal microscopy to determine the film thickness within a falling film microreactor used for the hydrogenation of nitrobenzene [110]. Depending on the liquid flow rate, volumetric mass transfer coefficients of $k_{\mathrm{L}} a=3-$ $8 \mathrm{~s}^{-1}$ were estimated.

Claudel et al. used gas/liquid chemical reaction and physical absorption to study the mass transfer performances of microstructured film reactors for different flow rates of gases and liquids [111]. The mass transfer coefficient was found to be strongly depended on the flow rates and was in the range of $4 \times 10^{-4}<k_{\mathrm{L}}<10^{-3} \mathrm{~m} / \mathrm{s}$. The specific interfacial area was determined to be from 6000 to $9000 \mathrm{~m}^{2} / \mathrm{m}^{3}$ (liquid volume) corresponding to $180-200 \mathrm{~m}^{2} / \mathrm{m}^{3}$ referred to the reactor volume.

The MSR presented above for multiphase systems were designed for fast reactions. Recently, Abdallah et al. [112] described a microstructured mesh contactor with residence times from few seconds up to hours (Fig. 16). The microcontactor [113] has two $100 \mu \mathrm{m}$ deep cavities for the gas (hydrogen) and the
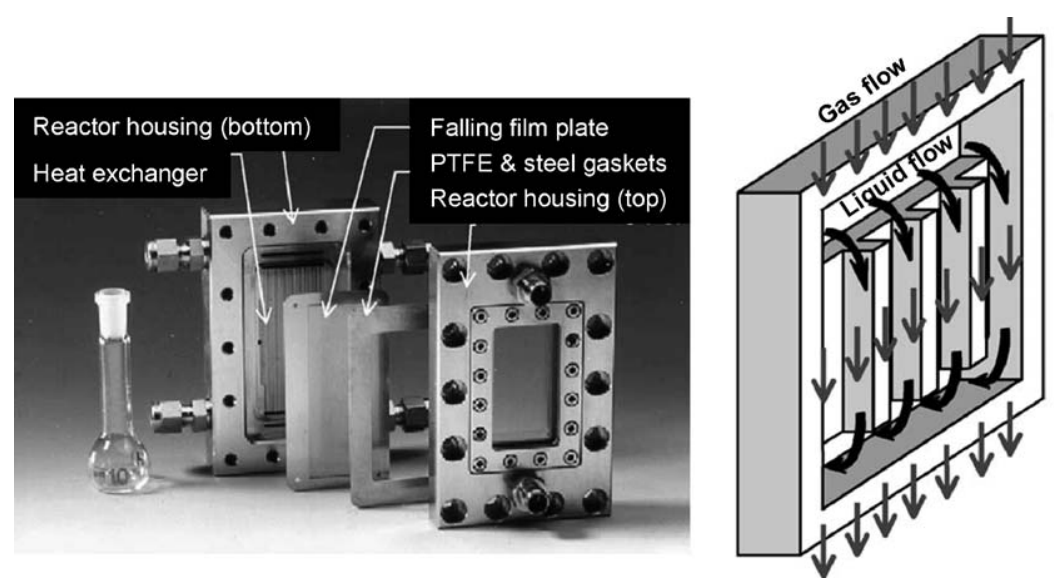

Fig. 15. Components and scheme of the microstructured falling film reactor [108]. 


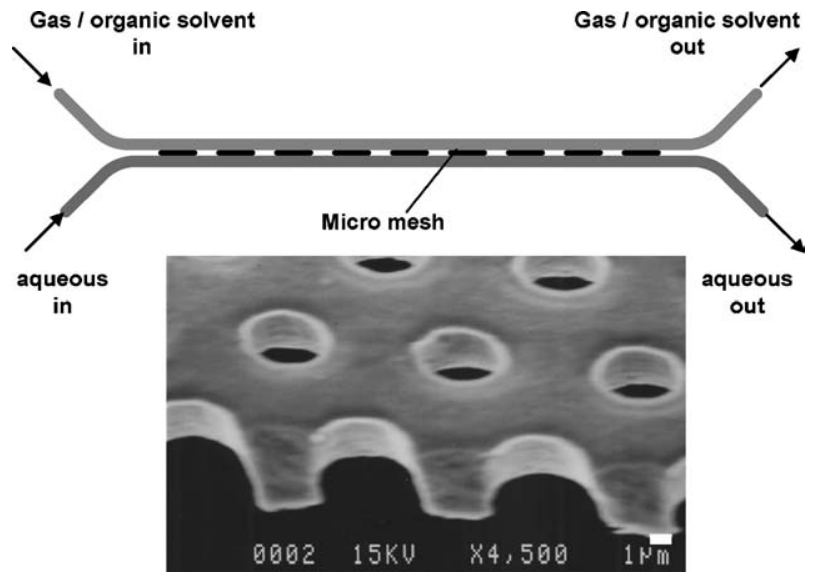

Fig. 16. Principle of two-phase microcontactor and SEM of the micromesh [113].

reacting liquid separated by a micromesh. Twenty to twenty-five percent of the mesh surface consists of small $5 \mu \mathrm{m}$ holes resulting in a gas/liquid interphase of ca. $2000 \mathrm{~m}^{2} / \mathrm{m}^{3}$ referred to the liquid. This design allows high volumetric mass transfer while stabilizing the gas/liquid interphase. The micromesh reactor was used for gas-liquid-solid hydrogenations and gasliquid asymmetric hydrogenations. Applications for catalyst/ chiral inductor screening and for kinetic data acquisition were demonstrated [112].

\section{Summary and outlook}

Microreactors are more and more recognized in recent years as a novel tool for chemistry and chemical process industry. They are also finding applications in the field of biochemistry and drug discovery. Different reactions have been used to illustrate the advantages of performing chemical reactions in microreactors, which are particularly suited for highly exothermic and fast reactions. The temperature control significantly reduces side reactions and prevents hot-spots formation. Higher reaction temperatures are attained leading to reduced reaction volumes and the use of lower amount of catalyst. This improves the process energy efficiency and reduces the operational cost. Moreover, broader reaction conditions, including up to the explosion regime, can be afforded. The small diameters of the reactor channels ensure a short radial diffusion time leading to a narrow residence time distribution. This is advantageous for consecutive processes since a high selectivity to the desired intermediate is achieved. In addition, the small inventories of reactants and products lead to inherent safety during the reactor operation.

Although microstructured techniques have been shown suitable for optimization of many synthetic procedures, they have not yet received enough attention for catalytic chemistry. The main reason for this is the difficulty of the introduction of solid catalyst into microchannels. Micro-packed-bed reactors are easy to fabricate, but usually have a high-pressure drop during the passage of gases. Therefore, catalytic wall microreactors are more suitable. An alternative design for achieving fluid patterns as in multichannel microstructured reactors is the "string reactor" where the microchannels are formed between the catalytic parallel filaments or wires.

Based on the research carried out up to now, there is a clear picture of the advantages and limits for the use microreactors for catalytic reactions, especially for commercial applications. It is expected that industry may share in this fascinating area of research and contribute to new developments.

\section{References}

[1] V. Hessel, H. Löwe, Chem. Eng. Technol. 26 (2003) 13.

[2] V. Hessel, H. Löwe, Chem. Eng. Technol. 26 (2003) 391.

[3] V. Hessel, H. Löwe, Chem. Eng. Technol. 26 (2003) 531.

[4] K. Jähnisch, M. Baerns, V. Hessel, H. Löwe, Angewandte Chemie - Int. Edition 43 (2004) 406.

[5] W. Ehrfeld, V. Hessel, V. Haverkamp, Microreactors, in Ullman's Encyclopedia of Industrial Chemistry, Wiley-VCH, Weinheim, 1999.

[6] K. Schubert, W. Bier, J. Brandner, M. Fichtner, C. Franz, G. Linder, in: Proceedings of Second International Conference on Microreaction Technology (IMRET2), New Orleans, USA, 1998), p. 88.

[7] G. Kolb, V. Hessel, Chem. Eng. J. 98 (2004) 1.

[8] S. Hardt, W. Ehrfeld, K.M.v.d. Bussche, Strategies for size reduction of microreactors by heat transfer enhancement effects, in: W. Ehrfeld, U. Eul, R.S. Wegeng (Eds.), Proceedings of the Fourth International Conference on Microreaction Technology (IMRET4), AIChE:, Atlanta, USA, 2000, p. 432.

[9] C. Alépée, L. Paratte, P. Renaud, R. Maurer, A. Renken, Fast heating and cooling for high temperature chemical microreactors, in: W. Ehrfeld (Ed.), Proceedings of the Fourth International Conference on Microreaction Engineering, Springer, Berlin, 2000, p. 514.

[10] C. Alépée, L. Vulpescu, P. Cousseau, P. Renaud, R. Maurer, A. Renken, Microsystem for high temperature gas phase reactions, in: W. Ehrfeld, U. Eul, R.S. Wegeng (Eds.), Proceedings of the Fourth International Conference on Microreaction Technology (IMRET 4), AIChE, Atlanta, 2000, p. 71.

[11] W. Ehrfeld, V. Hessel, H. Löwe, Extending the knowledge base in microfabrication towards chemical engineering and fluid dynamic simulation, in: W. Ehrfeld, U. Eul, R.S. Wegeng (Eds.), Proceedings of the Fourth International Conference on Microreaction Technology (IMRET 4), AIChE, Atlanta, USA, 2000, p. 3.

[12] U. Hagendorf, M. Janicke, F. Schüth, K. Schubert, M. Fichtner, in: Proceedings of the Second International Conference on Microreaction Technology (IMRET2), New Orleans, USA, 1998), p. 81.

[13] G. Veser, G. Friedrich, M. Freygang, R. Zengerle, A modular microreactor design for high-temperature catalytic oxidation reactions, in: W. Ehrfeld (Ed.), Proceedings of the Third International Conference on Microreaction Technology (IMRET3), Springer, Berlin, 2000, p. 674.

[14] G. Veser, J. Frauhammer, Chem. Eng. Sci. 55 (2000) 2271.

[15] G. Veser, Chem. Eng. Sci. 56 (2001) 1265.

[16] S.K. Ajmera, M.W. Losey, K.F. Jensen, M.A. Schmidt, AIChE J. 47 (2001) 1639.

[17] T. Bayer, J. Jenck, M. Matlosz, Chemie-Ingenieur-Technik 76 (2004) 528.

[18] S. Hasebe, Comput. Chem. Eng. 29 (2004) 57.

[19] M. Matlosz, J.-M. Commenge, Chimia 56 (2002) 654.

[20] F. Becker, et al. in: Proceedings of the International Conference on Microreaction Technology (IMRET 8), Atlanta, USA, 2005.

[21] U. Rodemerck, P. Ignaszewski, M. Lucas, P. Claus, M. Baerns, in: Proceedings of the Third International Conference on Microreaction Technology IMRET 3, Frankfurt, 2000), p. 287.

[22] K.F. Jensen, Chem. Eng. Sci. 56 (2001) 293.

[23] S.K. Ajmera, C. Delattre, M.A. Schmidt, K.F. Jensen, J. Catal. 209 (2002) 401

[24] M.W. Losey, S. Isogai, M.A. Schmidt, K.F. Jensen, in: Proceedings of the Fourth International Conference on Microreaction Technology (IMRET 4), Atlanta, 2000), p. 416. 
[25] C. Cao, G. Xia, J. Holladay, E. Jones, Y. Wang, Appl. Catal. A: Gen. 262 (2004) 19.

[26] C.S. Cao, Y. Wang, J.D. Holladay, E.O. Jones, D.R. Palo, AIChE J. 51 (2005) 982.

[27] J.D. Holladay, E.O. Jones, R.A. Dagle, G.G. Xia, C. Cao, Y. Wang, J. Power Sources 131 (2004) 69.

[28] VDI-Wärmeatlas, 9, Verein Deutscher Ingenieure, Berlin, Heidelberg, New York, 2002.

[29] P. Léger. Thermal and pressure drop characterization of a microstructured reactor for fast temperature cycling. Master thesis Ecole polytechnique fédérale de Lausanne, 2005.

[30] M. Baerns, H. Hoffmann, A. Renken, Chemische Reaktionstechnik, Wiley-VCH, Weinheim, Germany, 1999.

[31] A. Rouge, B. Spoetzl, K. Gebauer, R. Schenk, A. Renken, Chem. Eng. Sci. 56 (2001) 1419.

[32] J.M. Commenge, A. Rouge, A. Renken, J.P. Corriou, M. Matlosz, Récents Progrés en Génie des Procédés 15 (2001) 329.

[33] J.M. Commenge, L. Falk, J.P. Corriou, M. Matlosz, AIChE J. 48 (2002) 345.

[34] E.R. Delsman, M.H.J.M. De Croon, A. Pierik, G.J. Kramer, P.D. Cobden, C. Hofmann, V. Cominos, J.C. Schouten, Chem. Eng. Sci. 59 (2004) 4795.

[35] B. Platzer, T. Roßmann, Y. Xu, R. Födisch, D. Hönicke, Chem. Eng. Technol. 26 (2003) 765.

[36] J.C. Ganley, K.L. Riechmann, E.G. Seebauer, R.I. Masel, J. Catal. 227 (2004) 26.

[37] D. Hönicke, G. Wiessmeier, DECHEMA Monographs, Microsyst. Technol. Chem. Biol. Microreact. 132 (1996) 93.

[38] G. Wiessmeier, D. Hönicke, J. Micromech. Microeng. 6 (1996) 285.

[39] G. Wiessmeier, K. Schubert, D. Hönicke, Monolithic microstructure reactors possessing regular mesopore systems for the successful performance of heterogeneously catalyzed reactions, in: W. Ehrfeld (Ed.), Proceedings of the First International Conference on Microreaction Technology (IMRET 1), Springer, Berlin, 1997, p. 20.

[40] Y. Suzuki, J. Saito, N. Kasagi, JSME International Journal Series BFluids and Thermal Engineering 47 (2004) 522.

[41] P. Reuse. Production d'hydrogène dans un réacteur microstructuré. Couplage themique entre le steam reforming et l'oxydation totale du méthanol. Thesis No. 2830, Ecole polytechnique fédérale de Lausanne, 2003.

[42] I. Aartun, T. Gjervan, H. Venvik, O. Gorke, P. Pfeifer, M. Fathi, A. Holmen, K. Schubert, Chem. Eng. J. 101 (2004) 93.

[43] Y. Wang, Y.H. Chin, R.T. Rozmiarek, B.R. Johnson, Y. Gao, J. Watson, A.Y.L. Tonkovich, D.P. Vander Wiel, Catal. Today 98 (2004) 575.

[44] P. Reuse, P. Tribolet, L. Kiwi-Minsker, A. Renken, Catalyst coating in microreators for methanol steam reforming: kinetics, in: W. Ehrfeld (Ed.), Proceedings of the Fifth International Conference on Microreaction Engineering (IMRET 5), Springer, Strasbourg, 2001, p. 322.

[45] P. Reuse, A. Renken, K. Haas-Santo, O. Gorke, K. Schubert, Chem. Eng. J. 101 (2004) 133.

[46] S.A. Mitchenko, E.V. Khomutov, A.A. Shubin, Y.M. Shul'ga, J. Mol. Catal. A: Chem. 212 (2004) 345.

[47] L.A. Isupova, et al. Kinet. Catal. 43 (2002) 129.

[48] J. Bravo, A. Karim, T. Conant, G.P. Lopez, A. Datye, Chem. Eng. J. 101 (2004) 113

[49] D.J. Seo, W.-L. Yoon, Y.-G. Yoon, S.-H. Park, G.-G. Park, C.-S. Kim, Electrochim. Acta 50 (2004) 715.

[50] G.-G. Park, D.J. Seo, S.-H. Park, Y.-G. Yoon, C.-S. Kim, W.-L. Yoon, Chem. Eng. J. 101 (2004) 87.

[51] I. Yuranov, N. Dunand, L. Kiwi-Minsker, A. Renken, Appl. Catal. B: Environ. 36 (2002) 183.

[52] C.J. Brinker, G.W. Scherer, Sol-Gel Science, Academic Press, 1990.

[53] M.S. Lim, M.R. Kim, J. Noh, S.I. Woo, J. Power Sources 140 (2005) 66.

[54] J. Coronas, J. Santamaria, Chem. Eng. Sci. 59 (2004) 4879.

[55] U. Hiemer, E. Klemm, F. Scheffler, T. Selvam, W. Schwieger, G. Emig, Chem. Eng. J. 101 (2004) 17.

[56] E.V. Rebrov, G.B.F. Seijger, H.P.A. Calis, M.H.J.M. de Croon, C.M. van den Bleek, J.C. Schouten, Appl. Catal. A: Gen. 206 (2001) 125.

[57] M.T. Janicke, H. Kestenbaum, U. Hagendorf, F. Schuth, M. Fichtner, K. Schubert, J. Catal. 191 (2000) 282.
[58] H.Y. Chen, L. Chen, Y. Lu, Q. Hong, H.C. Chua, S.B. Tang, J. Lin, Catal. Today 96 (2004) 161.

[59] W.J. Stark, K. Wegner, S.E. Pratsinis, A. Baiker, J. Catal. 197 (2001) 182.

[60] T. Johannessen, S. Koutsopoulos, J. Catal. 205 (2002) 404.

[61] J.R. Jensen, T. Johannessen, S. Wedel, H. Livbjerg, J. Catal. 218 (2003) 67.

[62] S. Thybo, S. Jensen, J. Johansen, T. Johannessen, O. Hansen, U.J. Quaade, J. Catal. 223 (2004) 271.

[63] S. Schimpf, M. Bron, P. Claus, Chem. Eng. J. 101 (2004) 11

[64] R. Knitter, M.A. Liauw, Lab Chip 4 (2004) 378.

[65] O. Wolfrath, L. Kiwi-Minsker, P. Reuse, A. Renken, Ind. Eng. Chem. Res. 40 (2001) 5234.

[66] O. Wolfrath, L. Kiwi-Minsker, A. Renken, Filamenteous catalytic beds for the design of membrane microreactor: propane dehydrogenation as a case study, in: W. Ehrfeld (Ed.), Proceedings of the Fifth International Conference on Microreaction Engineering (IMRET 5), Springer, Strasbourg, 2001, p. 191.

[67] L. Kiwi-Minsker, O. Wolfrath, A. Renken, Chem. Eng. Sci. 57 (2002) 4947.

[68] C. Horny, L. Kiwi-Minsker, A. Renken, in: Proceedings of the Third International Symposium on Multifunctional Reactors (ISMR3), Bath, August 27-29, 2003), p. 48.

[69] C. Horny, L. Kiwi-Minsker, A. Renken, Chem. Eng. J. 101 (2004) 3.

[70] J. Jenkins, E. Shutt, Platinum Met. Rev. 33 (1989) 118.

[71] K. Geissler. Wasserstoffgewinnung aus Methanol für PEM-Brennstoffzellen-Anwendung. Thesis No 2442, Ecole polytechnique fédérale de Lausanne, 2002

[72] L. Kiwi-Minsker, Chimia 56 (2002) 143.

[73] C. Horny. Développement d'un réacteur microstructuré basé sur des filaments métalliques catalytiques. Production autotherme d'hydrogène par steam-reforming oxydatif du méthanol. Thesis No 3271, Ecole polytechnique fédérale de Lausanne, 2005

[74] J. Lojewska, A. Kolodziej, P. Dynarowicz-Latka, A. Weselucha-Birczynska, Catal. Today 101 (2005) 81.

[75] B. Monnerat. Production d'hydrogène en regime périodique à partir d'hydrocarbures sur des catalyseurs structurés. Thesis No 2400, Ecole polytechnique fédérale de Lausanne, 2001

[76] B. Monnerat, L. Kiwi-Minsker, A. Renken, Chem. Eng. Sci. 56 (2001) 633.

[77] B. Monnerat, L. Kiwi-Minsker, A. Renken, Chem. Eng. Sci. 58 (2003) 4911.

[78] I. Yuranov, A. Renken, L. Kiwi-Minsker, Appl. Catal. 281 (2005) 55.

[79] T. Boger, A.K. Heibel, Chem. Eng. Sci. 60 (2005) 1823.

[80] M. Schuessler, M. Portscher, U. Limbeck, Catal. Today 79 (2003) 511.

[81] J.-M. Bae, S. Ahmed, R. Kumar, E. Doss, J. Power Sources 139 (2005) 91.

[82] C. Alepée, L. Vulpescu, P. Cousseau, P. Renaud, R. Maurer, A. Renken, Measure. Control 33 (2000) 265.

[83] R. Maurer, A. Renken, Trans IChemE Part A 81 (2003) 730.

[84] P.L. Silveston, R.R. Hudgins, A. Renken, Catal. Today 25 (1995) 91.

[85] A. Rouge, A. Renken, Studies Surf. Sci. Catal. 133 (2001) 239.

[86] J.J. Brandner, G. Emig, M.A. Liauw, K. Schubert, Chem. Eng. J. 101 (2004) 217.

[87] S. Jensen, J.L. Olsen, H. Hansen, U.J. Quaade, in: Proceedings of the International Conference on Microreaction Technology (IMRET 8), Atlanta, USA, 2005

[88] V. Hessel, H. Lowe, F. Schonfeld, Chem. Eng. Sci. 60 (2005) 2479.

[89] G.N. Doku, W. Verboom, D.N. Reinhoudt, A. van den Berg, Tetrahedron 61 (2005) 2733.

[90] H. Pennemann, V. Hessel, H. Löwe, P. Watts, S.J. Haswell, Org. Process Res. Develop. 8 (2004) 422.

[91] G. Dummann, U. Quittmann, L. Groschel, D.W. Agar, O. Worz, K. Morgenschweis, Catal. Today 79/80 (2003) 433.

[92] J. Antes, D. Boskovic, H. Krause, S. Loebbecke, N. Lutz, T. Tuercke, Chem. Eng. Res. Design 80 (2003) 760.

[93] M.-A. Schneider, T. Maeder, P. Ryser, F. Stoessel, Chem. Eng. J. 101 (2004) 241. 
[94] C.I. Jönsson, S. Lundgren, S.J. Haswell, C. Moberg, Tetrahedron 60 (2004) 10515.

[95] Y. Önal, M. Lucas, P. Claus, Chemie-Ingenieur-Technik 77 (2005) 101.

[96] R. Abdallah, C. De Bellefon, T. Ireland, Chemie-Ingenieur-Technik 76 (2004) 633.

[97] C. Basheer, F. Shahitha, J. Hussain, H.K. Lee, S. Valiyaveettil, Tetrahedron Lett. 45 (2004) 7297.

[98] C. Basheer, H.K. Lee, S. Valiyaveettil, S. Swaminathan, Chem. Commun. 11 (2005) 409.

[99] J.C. Jansen, G.M.V. Rosmalen, J. Crystals Growth 128 (1993) 1150.

[100] B.J. Schoeman, A. Erdem-Senatalar, J. Hedlund, J. Sterte, Zeolites 19 (1997) 21.

[101] Y.S.S. Wan, A. Gavriilidis, J.L.H. Chau, K.L. Yeung, J. Catal. 223 (2004) 241.

[102] M. Miyazaki, J. Kaneno, R. Kohama, M. Uehara, K. Kanno, M. Fujii, H. Shimizu, H. Maeda, Chem. Eng. J. 101 (2004) 277.

[103] M. Brivio, R.E. Oosterbroek, W. Verboom, M.H. Goedbloed, A. van den Berg, D.N. Reinhoudt, Chem. Commun. (2003) 1924.

[104] G. Centi, S. Perathoner, Catal. Today 79 (2003) 3.
[105] N. Yoswathananont, K. Nitta, Y. Nishiuchi, M. Sato, in: Proceedings of the International Conference on Microreaction Technology (IMRET 8), Atlanta, USA, 2005.

[106] M.K. Akbar, D.A. Plummer, S.M. Ghiaasiaan, Int. J. Multiphase Flow 29 (2003) 855

[107] J. Kobayashi, Y. Mori, K. Okamoto, R. Akiyama, M. Ueno, T. Kitamori, S. Kobayashi, Science 304 (2004) 1305

[108] K.K. Yeong, A. Gavriilidis, R. Zapf, V. Hessel, Catal. Today 81 (2003) 641.

[109] J.W. Lee, K.K. Yeong, A. Gavriilidis, R. Zapf, V. Hessel, in: Proceedings of the International Conference on Microreaction Technology (IMRET 8), Atlanta, USA, 2005.

[110] K.K. Yeong, A. Gavriilidis, R. Zapf, V. Hessel, Chem. Eng. Sci. 59 (2004) 3491.

[111] S. Claudel, C. Nikitine, C. Boyer, P. Font, in: Proceedings of the International Conference on Microreaction Technology (IMRET 8), Atlanta, USA, 2005.

[112] R. Abdallah, V. Meille, C. De Bellefon, J. Shaw, D. Wenn, Chem. Commun. 10 (2004) 372.

[113] D.A. Wenn, J.E.A. Shaw, B. Mackenzie, Lab Chip (2003) 180. 